\title{
PRODUÇÃO DE MUDAS DE ORQUÍDEAS A PARTIR DE SEMENTES IN VITRO E SUA VIABILIDADE ECONÔMICA: ESTUDO DE CASO
}

\author{
GIULIO CESARE STANCATO ${ }^{1}$; PAUL FRANS BEMELMANS ${ }^{2}$ e CELSO LUIS RODRIGUES VEGRO²
}

\section{RESUMO}

A propagação de orquídeas, a partir de sementes, in vitro, constitui uma das formas mais disseminadas de multiplicação das espécies botânicas na família Orchidaceae. O objetivo deste trabalho foi obter o custo operacional da produção de mudas de orquídeas, com base no estudo de caso representado pelo Laboratório de Cultura de Tecidos de Plantas, na Seção de Orquidário do Estado, no Instituto de Botânica, em São Paulo. Os resultados indicam que essa forma de produção apresenta uma rentabilidade de $52 \%$, com custo unitário da muda estimado em $\mathrm{R} \$ 0,65$.

Palavras-chave: cultivo assimbiótico, plântulas, custo operacional.

\section{ABSTRACT \\ Orchids seedling production in vitro and its economical viability: study case}

The orchids propagation by seed in vitro is a disseminated form to multiplication of the botanical species in the Orchidaceae. The objective of this work was to evaluate the orchid seedling production through the case exemplified by the Orchid Tissue Culture Laboratory in the Botanical Institute, São Paulo, Brazil. The results show that the cost of production represented $52 \%$ of the rentability and the price of the only seedling is the $\mathrm{R} \$ 0,65$.

Key-words: asymbiotic cultive, seedlings, operative cost.

\section{INTRODUÇÃO}

A Orchidaceae é, provavelmente, a maior família botânica entre as plantas superiores. Estão descritas, atualmente, em torno de 25.000 espécies e produzidos outros tantos híbridos por cruzamento de espécies selvagens e cultivadas (SUTTLEWORTH et al., 1970). Na floricultura, sua presença se faz marcante não apenas como plantas de vaso, mas, também, como flores de corte, muito apreciadas pela sua beleza e durabilidade. No Brasil, seu emprego tem aumentado progressivamente, já que o surgimento de técnicas de sua propagação e multiplicação tem-lhe possibilitado ampla comercialização.

A maioria das plantas, incluindo as orquídeas, pode ser reproduzida por duas vias: através da multiplicação vegetativa ou assexuada, onde uma parte da planta é separada e origina novo indivíduo com características idênticas, ou através da reprodução sexuada, como decorrência da polinização de uma flor e da recombinação do material genético. No habitat existe uma diversidade de características nas espécies de orquídeas; o "pool" de genes é tal que ocorrem variações na cor e no tamanho das flores, no vigor da planta, na habilidade em utilizar os nutrientes, na resistência às pragas e doenças, entre outras características. O processo natural de polinização ajuda a manter a mistura desse "pool" de genes, não permitindo o estreitamento da base genética e as chances de ocorrência de sua dilapidação.

Na natureza, a semente de orquídea germina e se desenvolve mediante uma relação simbiótica com fungos micorrízicos, os quais fornecem os nutrientes

\footnotetext{
${ }^{1}$ Instituto de Botânica, Secretaria do Meio Ambiente do Estado de São Paulo, Caixa Postal 4005, 01061-970 São Paulo (SP).

${ }^{2}$ Instituto de Economia Agrícola, Secretaria de Agricultura e Abastecimento do Estado de São Paulo, Avenida Miguel Estéfano, 3900, 04301-903 São Paulo (SP).
} 
necessários ao crescimento, até que a plântula possa realizar a fotossíntese e produzir o próprio alimento. $\mathrm{Na}$ cultura assimbiótica, a semente é colocada em um frasco contendo um meio de cultura estéril, o qual proporciona a germinação e o crescimento das mudas, pois possui todos os nutrientes necessários (ARDITTI \& ERNST, 1984). Dessa forma, grande número de mudas pode ser facilmente produzido, crescendo num ambiente controlado de modo artificial e totalmente estéril. A cultura assimbiótica in vitro é muito eficiente na germinação e cultivo de orquídeas epífitas tropicais e subtropicais, nas fases iniciais de crescimento.

A semeadura in vitro pode ser realizada com as sementes em dois estádios de maturação. No primeiro, espera-se a cápsula secar naturalmente e se abrir; no segundo, a cápsula é colhida ainda verde, antes da sua deiscência natural. Esse processo, conhecido como cultura de cápsula imatura ou verde, baseia-se no fato de que as sementes nesse estádio de crescimento germinam e produzem mudas, desde que a cápsula tenha ultrapassado dois terços do tempo entre a polinização e a abertura natural.

Com as florestas tropicais e subtropicais sendo destruídas e as restrições colocadas no comércio internacional de espécies, a propagação de orquídeas por meio de sementes é, talvez, a maneira mais importante de preservar espécies em cultivo e no seu habitat. Atualmente, constitui um processo rotineiro, com muitas espécies literalmente salvas da extinção.

A demanda crescente por plantas e flores de orquídeas tem obrigado os produtores a comprar mudas de laboratórios especializados, os quais tendem a diminuir o seu custo de produção. $O$ investimento em material, na infra-estrutura e na mão-de-obra treinada, obriga esses laboratórios a minimizar as perdas e a maximizar a utilização dos fatores envolvidos na produção.

\subsection{Importância econômica do segmento de flores e plantas ornamentais}

A produção e a comercialização de flores e plantas ornamentais têm-se tornado um dos ramos mais dinâmicos da atividade agrícola de muitos países, notadamente na Holanda, que apenas nesse segmento apura faturamento superior a 7 bilhões de dólares, ante uma produção pouco acima de 1 bilhão e meio de dólares (MATSUNAGA, 1995). De acordo com CASTRO (1998), o mercado mundial de flores e plantas ornamentais gera negócios que ultrapassam os 100 bilhões de dólares ao ano, considerando toda a cadeia produtiva. Países como EUA, Japão e Colômbia são grandes produtores e exportadores de flores de corte e plantas em vaso; já o consumo de flores de corte e plantas ornamentais é liderado pela Suíça e Noruega, com dispêndio anual acima de 150 dólares per capita, seguidos pela Alemanha, Áustria, Bélgica, Dinamarca, EUA, Finlândia, França, Holanda, Itália e Suécia, com consumo per capita na faixa de 50-110 dólares (MATSUNAGA, 1997; CASTRO, 1998). Em países do MERCOSUL, o consumo per capita de flores de corte e plantas ornamentais está aquém desses níveis: 25 dólares na Argentina e apenas 6 dólares no Brasil (CASTRO, 1998).

O consumo de flores de orquídeas no Japão força o incremento da produção local com importações, sobretudo de países como Austrália, Nova Zelândia e Tailândia, sendo esse último o principal fornecedor do mercado japonês, especializando-se no cultivo de orquídeas em vaso.

Apesar do sucesso alcançado com a produção de crisântemo, gladíolo, violeta e rosa, o Brasil pode ainda ser considerado um mercado emergente tanto para a produção como para o consumo de flores e plantas ornamentais. Segundo MATSUNAGA (1995), prevalecem, no País, pequenas áreas com reduzida aplicação de capital, baixo valor unitário, falta de tradição nas exportações, qualidade abaixo dos parâmetros internacionais e mão-de-obra pouco qualificada. Para esse autor, tal conjunto de obstáculos tem impedido o Brasil de também se tornar importante concorrente no mercado internacional de flores e de plantas ornamentais; adicionalmente, encontra-se distante dos principais mercados consumidores, o que torna sua oferta pouco competitiva, decorrente da substancial participação, no preço final, do oneroso frete aéreo.

Em 1994, a estimativa era de que o mercado brasileiro de flores e de plantas ornamentais alcançasse cerca de 600 milhões de dólares (MATSUNAGA, 1995). Em 1997, o País possuía 4.500 ha cultivados, com 3.600 produtores desenvolvendo essa produção (MATSUNAGA, 1997). Estimativas prevêem que esse mercado tenha ultrapassado o patamar de um bilhão de dólares, em 1999, esboçando uma taxa de crescimento acima dos 20\% ao ano (ARRUDA et al., 1996). No Estado de São Paulo, concentram-se cerca de $70 \%$ da produção nacional de flores e plantas ornamentais (KÄMPF, 1997). 
Também nesse Estado, concentram-se os maiores centros de distribuição de flores e plantas ornamentais, listando-se a Companhia de Entrepostos e Armazéns Gerais de São Paulo (CEAGESP), a Central de Abastecimento S.A. (CEASA), em Campinas, e o Veiling, na Holambra. MATSUNAGA (1997) estimou que nesses entrepostos atacadistas, o valor global transacionado atingiu 267,6 milhões de dólares. Finalmente, ressalta-se o caráter intrínseco de geração de renda e de emprego propiciados pela atividade, estimando-se que nela são gerados 28,5 mil empregos (ARRUDA et al., 1996).

Após o programa de estabilização da moeda, implantado em meados de 1994, observou-se profunda modificação nos hábitos de consumo da população brasileira, que, além de consumir mais proteínas, mais eletroeletrônicos, mais automóveis, etc., passou também a demandar mais flores e plantas ornamentais. Todavia, o caráter dessa demanda alterou-se, pois foi introduzido o conceito da novidade, além da exigência de produtos com maior qualidade e preços mais competitivos. Esse fenômeno permitiu a sustentação da referida taxa de crescimento da produção.

Entretanto, o segmento de orquídeas diferencia-se ligeiramente do conjunto das flores e plantas ornamentais, pois há maior especialização em cada fase do processo produtivo e a produção de mudas in vitro já se está consolidando, quer por motivos econômicos, quer pela garantia de qualidade e homogeneidade do produto final.

\subsection{Aspectos técnicos da produção de mudas de orquídeas in vitro}

A multiplicação e a produção de mudas de orquídeas são realizadas, principalmente, em laboratórios, em vista da exigência de condições assépticas durante seu desenvolvimento. Há maior número de laboratórios nos Estados de São Paulo, Rio de Janeiro, Minas Gerais, Rio Grande do Sul e Santa Catarina, os quais são especializados somente em mudas vendidas para o resto do País. Essas mudas são obtidas a partir de sementes ou através de técnicas especiais de cultura de tecidos de plantas. As técnicas conhecidas como micropropagação chegaram ao Brasil há pouco mais de 25 anos, sendo que sua importância, principalmente a cultura de meristema, foi aumentar a quantidade de mudas produzidas e, assim, diminuir o preço das plantas, contribuindo, ainda, para salvar muitas espécies de orquídeas da extinção.

O Brasil reúne todas as condições favoráveis ao desenvolvimento da orquidofilia com fins comerciais, estando entre elas a posição geográfica privilegiada, que permite o cultivo de orquídeas interessantes à floricultura. Segundo KERBAUY (1996), falta ao País, no entanto, tecnologia para competir no mercado externo. O comércio de plantas de orquídeas em florescimento é destinado ao público que aprecia flores em geral e não somente as orquídeas; também existe uma pequena demanda para orquídeas com flores de corte. Orquidófilos e orquidólogos, porém, que cultivam determinados gêneros ou espécies, adquirem plantas principalmente na fase de muda, chegando, inclusive, a importar frascos de cultivo com plântulas. Esse comércio em especial é o que movimenta maior volume de recursos.

Quanto à sua aplicação, a micropropagação de orquídeas sempre exige um ajuste da técnica empregada às peculiaridades das muitas espécies e dos milhares de híbridos criados a partir delas. Geralmente, na semeadura assimbiótica, as sementes são incubadas em meio nutritivo (KNUDSON, 1946, ou VACIN \& WENT, 1949), em frascos livres da contaminação por microrganismos. Após o período de germinação, as plântulas são transferidas sucessivamente para outros frascos, em cultivos intermediários chamados repicagens, cujo objetivo é minimizar os efeitos da competição que se estabelece dentro do frasco. No laboratório da Seção de Orquidário do Estado, no Instituto de Botânica, estão sendo obtidos excelentes resultados com três repicagens sucessivas após a semeadura, sendo a possibilidade de contaminação maior à medida que aumenta a manipulação e abertura dos frascos.

Nesse cenário introdutório que relata a importância econômica do setor de flores e plantas ornamentais, bem como aspectos técnicos da produção de mudas de orquídeas in vitro, denota-se grande interesse na expansão do mercado interno e também para o exterior na produção diferenciada de flores, aumentando a oferta interna e gerando alternativas de produção para atender a uma demanda crescente. Nesse enfoque, preocupações com custos de sistemas produtivos têm norteado os produtores e investidores no segmento. 
Este estudo se preocupa em oferecer uma contribuição na orientação de interessados na produção de flores com um olhar nos custos. Seu objetivo central é a elaboração do custo operacional para a produção de mudas de orquídea e sua viabilidade econômica. Como outros objetivos, também visa colocar à disposição dos produtores as noções básicas da técnica para a produção de mudas.

\section{MATERIAL E MÉTODOS}

O custo operacional utilizado na obtenção de mudas de orquídea é o proposto pelo Instituto de Economia Agrícola (MATSUNAGA et al., 1976), cuja estrutura básica consiste no dispêndio com mãode-obra, máquinas e material consumido, depreciação dos equipamentos e juros bancários.

As horas gastas em cada operação são as empregadas em condições experimentais, desde a polinização nas plantas matrizes para obtenção do fruto até a venda da muda.

A mão-de-obra considerada foi a comum para todas as operações, cujo salário bruto era de $\mathrm{R} \$ 500,00 /$ mês. Para os equipamentos e benfeitorias utilizados, quantificaram-se as horas de uso e calculou-se a depreciação, separadamente do custo diário. Consideraram-se como equipamentos e/ou benfeitorias um reservatório com capacidade para $45,0 \mathrm{~m}^{3}$ de água, um conjunto motobomba de $3,0 \mathrm{cv}$, um pulverizador costal manual, as instalações do laboratório de cultura de tecidos e da sala de germinação, um aparelho de ar condicionado com termostato, oito estantes de aço e o ripado para o cultivo das matrizes. O presente estudo é um corte temporal tendo por premissa aqueles indivíduos que já atuam na atividade de produção de mudas de plantas ornamentais.

Os coeficientes técnicos foram levantados junto à Seção de Orquidário, do Instituto de Botânica do Estado de São Paulo, em novembro de 1999.

Para o cálculo do custo horário dos equipamentos e/ou benfeitorias, levou-se em conta o reparo anual na proporção de 5 a $10 \%$ do valor total do bem (Tabela 1), o combustível ou energia, de acordo com a necessidade de equipamento, e a depreciação pelo método das cotas fixas ou da linha direta.
As orquídeas epífitas das regiões tropicais e subtropicais dos gêneros Laelia, Cattleya, Miltonia, Maxillaria e Oncidium, entre muitos outros, são mais bem conduzidas em ripados, em vasos de barro cerâmico, em lotes de matrizes, podendo-se obter, em cada matriz, um único fruto bem formado. A partir das suas sementes são produzidas cerca de 3.000 mudas, sendo necessário realizar as seguintes operações (Tabela 2):

a) polinização das flores;

b) cinco aplicações de fungicida e inseticida e cinco adubações, necessitando o total de 2,05 horas de mão-de-obra comum, utilizando um pulverizador costal manual;

c) regas com mangueira por doze meses, sendo efetuadas 156 regas, utilizando-se 24 horas de mão-deobra e mesmo tempo do reservatório e da bomba d'água;

d) coleta e esterilização do fruto, que é colhido verde e submetido imediatamente à esterilização superficial, com uso de $1 \mathrm{~h} 15 \mathrm{~min}$ de mão-de-obra e uma hora de laboratório;

e) semeadura e preparo do meio de cultura, sendo gastas 20 horas para a semeadura assimbiótica em frascos de vidro e mais 14,4 horas para o preparo do meio de cultura, com o mesmo tempo do uso do laboratório;

f) após a semeadura, os frascos permanecem cerca de três meses na sala de germinação, com o emprego de cinco horas de mão-de-obra, 1.170 horas do aparelho de ar condicionado e 2.834 horas nas estantes de aço;

g) a primeira repicagem consiste em transferir trinta plântulas para um frasco de vidro contendo o meio de cultura, gastando-se 8,30 horas de mão-deobra, 585 horas de uso do aparelho de ar condicionado e 2.196 horas nas estantes de aço;

h) na segunda repicagem, após três meses da primeira, são inoculadas quinze plântulas em outro frasco de vidro, com a reposição do meio de cultura, consumindo 16,67 horas de mão-de-obra, 455 horas de uso do aparelho de ar condicionado e 2.196 horas de estantes de aço;

i) a terceira repicagem, depois de três meses da segunda, colocam-se cinco plântulas em outro frasco de vidro, com a reposição do meio de cultura, permanecendo por mais três meses nessas condições. São utilizadas 41,67 horas de mão-de-obra, 455 horas de aparelho de ar condicionado e 2.196 horas nas estantes de aço; 


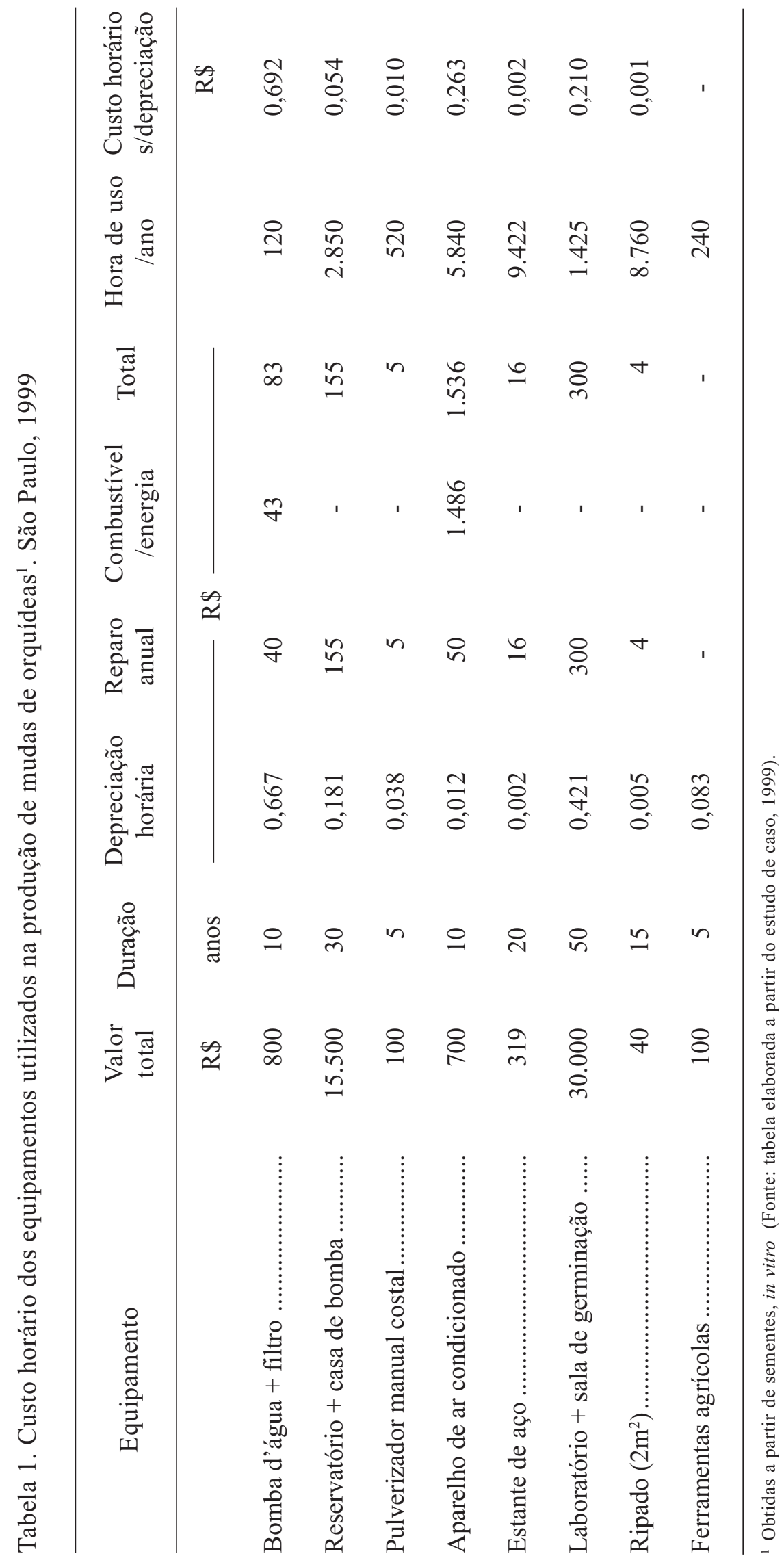


GIULIO CESARE STANCATO et al.

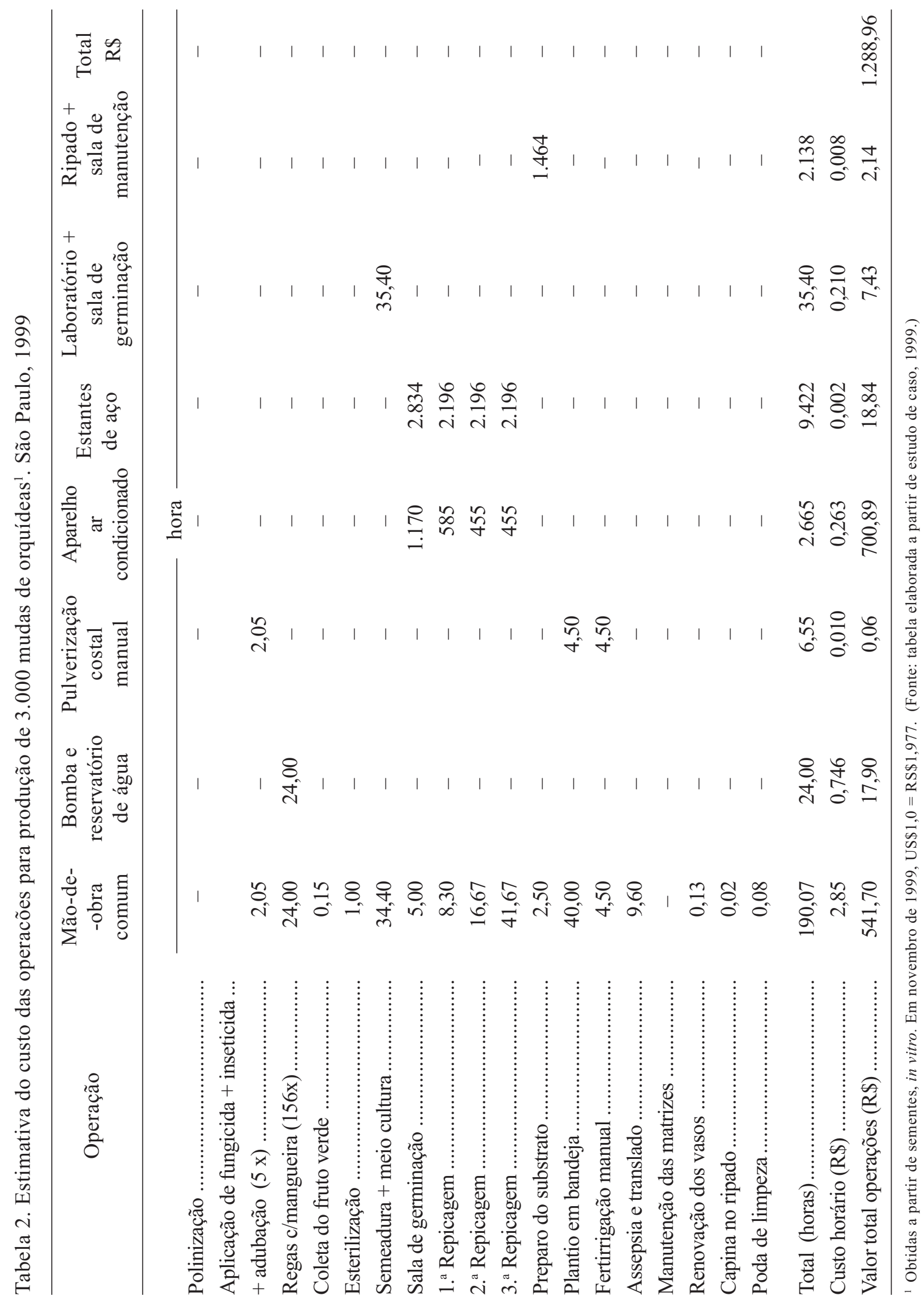


j) na aclimatação em ripado, efetuada a seguir, as mudas são transferidas para bandejas de 200 unidades (células), permanecendo aí por dois meses. Essa operação compreende o preparo do substrato, o plantio na bandeja e a repetição da fertirrigação por seis vezes. Gastam-se 47 horas de mão-de-obra e 450 horas de uso do pulverizador costal manual, acrescentando-se mais 9,6 horas para assepsia e translado ao ripado, o qual é utilizado durante 1.464 horas; k) para permitir o crescimento das plantas, realiza-se a manutenção das matrizes, durante a qual elas são reenvasadas, o que permite a produção de flores e a geração de novo fruto $(0,13$ hora). A partir daí, são necessárias cinco capinas no ripado $(0,02$ hora $)$ e duas podas de limpeza (0,08 hora). As matrizes consomem 674 horas de uso do ripado durante a operação de renovação dos vasos.

Tabela 3. Material e equipamentos utilizados na estimativa do custo operacional da produção de 3.000 mudas de orquídeas ${ }^{1}$. São Paulo, 1999

\begin{tabular}{|c|c|c|c|c|}
\hline Material & Unidade & Quantidade & Valor unitário & Total \\
\hline & & & & $\mathrm{R} S$. \\
\hline 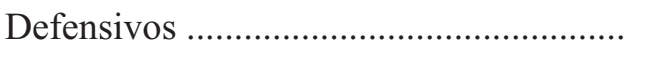 & - & - & - & - \\
\hline 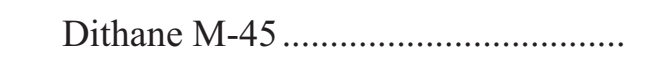 & $\mathrm{g}$ & 0,25 & 0,0126 & 0,003 \\
\hline 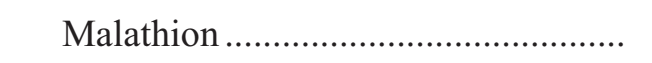 & $\mathrm{ml}$ & 0,30 & 0,0075 & 0,002 \\
\hline 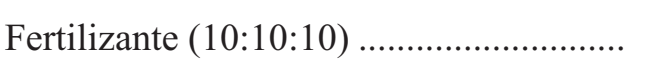 & $\mathrm{kg}$ & 0,48 & 0,343 & 0,165 \\
\hline 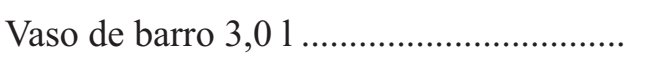 & pç & 3,00 & 3,00 & 9,000 \\
\hline Xaxim, substrato para as bandejas .......... & 1 & 0,015 & 35,00 & 0,525 \\
\hline Arame galvanizado $n .^{\circ} 16$ (4 anos) ......... & g & 6,08 & 8,00 & 0,012 \\
\hline Hipoclorito de sódio .................................. & 1 & 4,00 & 10,00 & 40,000 \\
\hline 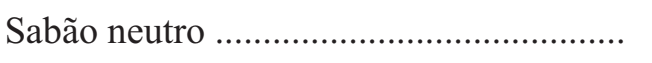 & $\mathrm{ml}$ & 1,00 & 0,012 & 0,012 \\
\hline Frasco para semeadura $(10$ anos $) \ldots \ldots \ldots . .$. & pç & 500,00 & 0,96 & 48,000 \\
\hline Filme de polipropileno ................................ & $\mathrm{m}^{2}$ & 65,85 & 0,83 & 54,66 \\
\hline Papel tipo kraft ..................................... & $\mathrm{m}^{2}$ & 24,70 & 0,30 & 7,410 \\
\hline 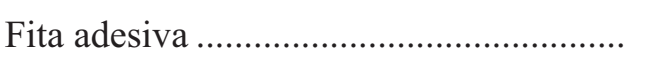 & rolo & 9,00 & 3,00 & 27,000 \\
\hline Meio de cultura V \& W .............................. & 1 & 27,90 & 8,00 & 223,20 \\
\hline Bandeja com 200 células .......................... & $\mathrm{pç}$ & 15 & 5,00 & 75,000 \\
\hline Xaxim, substrato para as matrizes ........... & 1 & 45 & 0,10 & 4,500 \\
\hline Esfagno & 1 & 45 & 0,10 & 4,500 \\
\hline Etiquetas de alumínio ................................... & $\mathrm{pç}$ & 40,00 & 0,10 & 4,000 \\
\hline Total do material .......................................... & - & - & - & 497,990 \\
\hline Custo operacional efetivo .......................... & - & - & - & $1.786,95$ \\
\hline 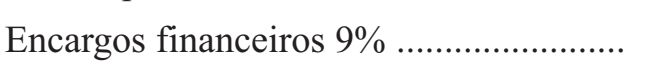 & - & - & - & 80,41 \\
\hline Depreciação dos equipamentos utilizados & - & - & - & 97,02 \\
\hline Custo operacional total .............................. & - & - & - & $1.964,38$ \\
\hline Custo operacional por muda ........................ & - & - & - & 0,65 \\
\hline
\end{tabular}

${ }^{1}$ Obtidas a partir de sementes, in vitro. Em novembro de 1999, US\$1,0 = RS\$1,977. (Fonte: tabela elaborada a partir de estudo de caso, 1999.) 


\section{RESULTADOS E DISCUSSÃO}

No custo horário dos equipamentos e/ou benfeitorias, levaram-se em conta os reparos, o gasto com combustível e a depreciação (Tabela 1). Esse custo horário foi aplicado sobre o total de horas na Tabela 2, alcançando $\mathrm{R} \$ 1.288,96$ a preços de novembro de 1999.

O material utilizado, como defensivos agrícolas, fertilizantes, vaso, xaxim, arame, hipoclorito de sódio, sabão neutro, frascos de vidro, filme de polipropileno, papel kraft, fita adesiva, meio de cultura (VACIN \& WENT, 1949), bandejas, esfagno e etiquetas de alumínio, foram quantificados (Tabela 3 ) de tal forma que, em alguns casos (vaso, arame, frasco de vidro) foi considerada a reutilização, por mais de um ano. O valor desse material totalizou $\mathrm{R} \$ 497,99$.

Somando-se todas essas operações, constituiuse o custo operacional efetivo, ou seja, um valor despendido em dinheiro de $\mathrm{R} \$ 1.786,95$ (Tabelas $2 \mathrm{e}$ 3 ), ao qual são adicionados os encargos financeiros, na base de $9 \%$ ao ano de juros, e a depreciação dos equipamentos e/ou benfeitorias utilizadas, chegandose ao custo operacional total de $\mathrm{R} \$ 1.964,38$. Portanto, para a produção de 3.000 mudas, chega-se ao custo de $\mathrm{R} \$ 0,65$ por unidade.

$\mathrm{O}$ que mais onerou o custo operacional foi o uso dos equipamentos e benfeitorias (Tabela 4), com $38,04 \%$, sendo o custo operacional do aparelho de ar condicionado o item que, individualmente, teve a maior participação no custo total, atingindo aproximadamente $\mathrm{R} \$ 700,00$, cerca de $35,68 \%$. Esse fato é decorrente do número de horas que o aparelho permanece ligado durante o ano, estimado em 2.655 horas e o custo da energia por ele consumida (Tabela 2). No item da infra-estrutura, os custos do laboratório e do reservatório, apesar de expressivos, não oneraram o total, em razão da a grande longevidade, estimando-se, para ambos, trinta anos de vida útil. A construção de um reserva-tório, valendo-se de obras de terraplanagem e filme negro de polipropileno, reduz os custos e a vida útil, resultando em pequena economia no custo total.

Tabela 4. Participação percentual dos itens de custo operacional na produção de 3.000 mudas de orquídeas ${ }^{1}$.

São Paulo, 1999

\begin{tabular}{|c|c|c|}
\hline \multirow{2}{*}{ Item de custo } & \multicolumn{2}{|c|}{ Custo operacional } \\
\hline & $(\mathrm{R} \$)$ & $\%$ \\
\hline Mão-de-obra ...................................... & 541,70 & 27,58 \\
\hline Equipamentos (operação) ............... & 747,26 & 38,04 \\
\hline Defensivos e assépticos ...................... & 40,02 & 2,04 \\
\hline 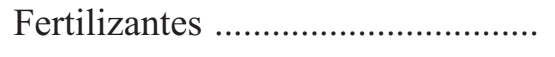 & 0,16 & 0,00 \\
\hline 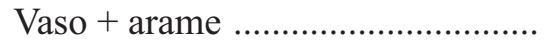 & 9,54 & 0,49 \\
\hline Meio de cultura V \& W .................... & 223,20 & 11,36 \\
\hline 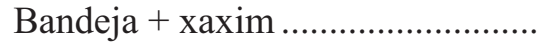 & 84,00 & 4,28 \\
\hline Frascos + selagem ………..................... & 137,07 & 6,98 \\
\hline 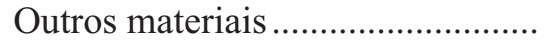 & 4,00 & 0,20 \\
\hline Custo operacional efetivo ............... & $1.786,95$ & 90,97 \\
\hline 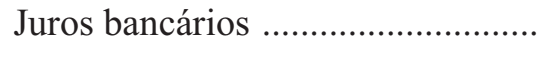 & 80,41 & 4,09 \\
\hline Depreciação $(9 \%)$ & 97,02 & 4,94 \\
\hline Custo operacional total ................... & $1.964,38$ & 100,00 \\
\hline
\end{tabular}

${ }_{1}^{1}$ Obtidas a partir de sementes in vitro. Em novembro de 1999, US\$1,0 $=$ RS\$1,977. (Fonte: Tabela elaborada a partir de estudo de caso, 1999.) 
A utilização da mão-de-obra ocupou o segundo lugar no custo total, com $\mathrm{R} \$ 541,70$ ou $27,58 \%$ (Tabela 4). Esse custo pode não se traduzir na realidade de outros casos e estudos semelhantes, uma vez que é notória a necessidade de mão-de-obra qualificada na condução das tarefas de laboratório. Tal profissional deveria possuir uma capacitação específica, sendo pouco encontrado no mercado e estando disponível apenas a custo mais expressivo.

Entre os materiais consumidos, o que mais onerou o custo total foi o meio de cultura (VACIN \& WENT, 1949). No caso estudado, seu custo foi de $\mathrm{R} \$ 223,20$, participando com $11,36 \%$ do total (Tabela 4). Nesse item, também pode-se pensar em substituições, dentro de certos limites, como a utilização de meios de cultura menos ricos em sais minerais; tal procedimento poderia refletir significativamente na redução do custo operacional.

Em condições normais de mercado, o preço da muda, no varejo, está ao redor de $\mathrm{R} \$ 1,00$, o que confere uma renda líquida de $\mathrm{R} \$ 1.035,62$ na venda de 3.000 mudas. É evidente que se o produtor conseguir obter melhor produtividade, pela incorporação de novas tecnologias e da racionalização do uso do material, poderá reduzir o custo operacional e melhorar sua competitividade no mercado.

\section{CONCLUSÕES}

O estudo de caso demonstra a viabilidade técnica e econômica da produção de mudas de orquídeas, in vitro, através de sementes. Os resultados indicam que, no caso estudado, é possível obter receita líquida de $52 \%$ nessa atividade (despesas menos receitas), uma vez que, para serem produzidas 3.000 mudas, há um dispêndio de $\mathrm{R} \$ 1.786,95$. Na ausência de benfeitorias, o interessado em iniciar-se nesse trabalho deve planejar sua imobilização, levando sempre em conta que os custos fixos serão permanentes e, por isso, exigirão pleno uso de sua capacidade, ao longo da vida útil. Por se tratar de estudo de caso, em situação específica de laboratório, chama-se a atenção para os resultados que devem ser analisados com cautela, servindo mais como indicativo do que conclusivo.

É possível que alguns itens e a infra-estrutura existente no Laboratório de Cultura de Tecidos da Seção de Orquidário do Estado tenham encarecido os custos; já, o gasto com a mão-de-obra, entre outros fatores, concorreu para o seu barateamento. Dessa forma, todos esses fatores devem ser cuidadosamente orçados pelo produtor, independentemente do início da sua produção comercial.

É importante lembrar que antes de iniciar-se nessa atividade, o produtor deverá realizar um estudo detalhado do mercado consumidor de mudas de orquídeas e definir quais as espécies mais apropriadas para a produção comercial: essa atenção pode significar o sucesso ou o fracasso do empreendimento.

\section{LITERATURA CITADA}

ARDITTI, J. \& ERNST, R. Physiology of germinating orchid seeds. In: ARDITTI, J. (ed). Orchid Biology : Reviews and Perspectives, v. 3. Ithaca: Cornell University Press, 1984. p.179-204.

ARRUDA, S. T.; OLIVETTE, M. P..A. \& CASTRO, C.E.F. Diagnóstico da floricultura no Estado de São Paulo. Revista Brasileira de Horticultura Ornamental, Campinas, v.2, n.2, p.1-18, 1996.

CASTRO, C.E.F. Cadeia produtiva de flores e plantas ornamentais. Revista Brasileira de Horticultura Ornamental, Campinas, v.4, n.1/2, p.1-46, 1998.

KÄMPF, A. N. A floricultura brasileira em números. Revista Brasileira de Horticultura Ornamental, Campinas, v.3, n.1, p.1-7, 1997.

KERBAUY, G. B. A produção de orquídeas. Revista Globo Rural, Rio de Janeiro, v.9, n. 10, p. 50-64, 1996.

KNUDSON, L. A new nutrient solution for germination of orchid seed. American Orchid Society Bulletin, Miami Beach, v.15, p.214-217, 1946.

MATSUNAGA, M. Floricultura como alternativa econômica na agricultura. Informações Econômicas, São Paulo, v.25, n.11, p.94-98, 1995.

MATSUNAGA, M. A indústria da flor no mundo e o comércio internacional no Brasil. Revista Brasileira de Horticultura Ornamental, Campinas, v.3, n.2, p.1-4, 1997.

MATSUNAGA, M.; BEMELMANS, P. F.; PEDROSO, I.; TOLEDO, P. E. N.; DULLEY, R. D. \& OKAWA, H. Metodologia de custos de produção utilizada pelo Instituto de Economia Agrícola (IEA). Agricultura em São Paulo, São Paulo, v.23, n.1, p.123-139, 1976.

SUTTLEWORTH, F.S.; ZIM. H. S.; DILLON, G. W. \& SMITH, E. W. Orchids. São Francisco: Western Publishing Company, Inc., 1970. 161p.

VACIN, E.F. \& WENT, F.W. Some pH changes in nutrient solutions. Botanical Gazette, Cambridge, v.110, p. 605$613,1949$. 